\title{
The treatment of haemorrhoids by rubber band ligation at St Mark's Hospital
}

\author{
P. J. JEFFERY \\ M.B., F.R.C.S.* \\ W. Miller \\ M.B., F.R.C.S.
}

\author{
ShEILA M. Ritchie \\ M.B. B.S. \\ P. R. HAWLEY \\ M.S., F.R.C.S.
}

St Mark's Hospital, London

Two hundred and ninety-five patients with symptomatic haemorrhoids were treated by rubber band ligation as out-patients at St Mark's Hospital, London, between April 1972 and December 1975. Follow-up was possible in 260 patients of whom two-thirds were satisfied with the outcome: 69 patients had residual symptoms for which no treatment had been sought. Nineteen patients eventually required a haemorrhoidectomy.

\section{Introduction}

The treatment of haemorrhoids has been of interest to surgeons since the Babylonian era (Eastman 1970). In this century, the injection of sclerosants into or above the haemorrhoids has been much used as an out-patient procedure although cryosurgery has been advocated recently. The usual operative technique has involved excision but anal dilatation and internal sphincterotomy have also had their advocates.

Rubber band ligation of internal haemorrhoids was introduced by Barron (1963), who recommended a modification of the out-patient technique first described by Blaisdell (1958). Since then, a number of authors have reported their results with this method (Salvati, 1970; Gehamy and Weakley, 1974; Panda et al., 1974; Steinberg, Liegois and AlexanderWilliams, 1975). This procedure reduces the tissue responsible for the production of symptoms by strangulation of the redundant mucosa. One or two haemorrhoids may be banded at any treatment session although a number of sessions may be required to obtain complete symptomatic relief. If rubber band ligation is well tolerated by patients, with a low incidence of complications and an acceptable recurrence rate, it would be an ideal

*Present address: Weymouth and District Hospital, Weymouth, Dorset. technique as both injection sclerotherapy and cryosurgery are not without their drawbacks.

There are financial advantages to both patients and country by treating symptomatic haermorrhoids in the out-patient department and avoiding inpatient surgery. This review was undertaken to determine if this treatment was effective and acceptable to the patient.

The results are based mainly on a subjective assessment by the patient. It was not thought necessary to recall patients for examination; Buie (1960) found that more than half of the patients over the age of 50 years admitted to the Mayo Clinic had proctoscopically evident, but not necessarily symptomatic, haemorrhoids. The object of treatment in patients with haemorroids is the relief of symptoms: the appearance of the anal canal is of secondary importance.

\section{Patients and methods}

The case records of all out-patients treated for symptomatic haemorrhoids by rubber band ligation at St Mark's Hospital between April 1972 and December 1975 were studied.

One hundred and thirty-four patients (Group 1) were treated by rubber band ligation only, while 161 patients (Group 2) had a combination of banding and injection. All patients underwent a course of treatment until symptoms subsided, each course consisting of a number of treatment sessions at one- to two-monthly intervals. At each session one or 2 haemorrhoids were banded. The method used was similar to that described by Groves, Evans and Alexander-Williams (1971).

\section{Results}

Of the 134 patients in Group 1, 83 had only one session of treatment, 36 required 2 sessions and 15 required 3 or more sessions for symptomatic relief. 
In Group 2, 114 of the 161 patients required one session of treatment, 34 needed 2 sessions and 13 , 3 or more sessions.

\section{Complications}

The early complications are shown in Table 1. The 3 patients with severe bleeding required admission to hospital.

Table 1. Early complications in 31 patients in Group 1 and 26 patients in Group 2

\begin{tabular}{lcc}
\hline Type of complication & $\begin{array}{c}\text { Group 1 } \\
\text { (134 patients) }\end{array}$ & $\begin{array}{c}\text { Group 2 } \\
\text { (161 patients) }\end{array}$ \\
\hline Severe bleeding & 3 & 0 \\
Minor bleeding & 10 & 5 \\
Pain or discomfort & 19 & 23 \\
\hline
\end{tabular}

TABLE 2. Final outcome in the 295 patients

\begin{tabular}{lcc}
\hline \multicolumn{1}{c}{ Outcome } & $\begin{array}{c}\text { Group 1 } \\
\text { (134 patients) }\end{array}$ & $\begin{array}{c}\text { Group 2 } \\
\text { (161 patients) }\end{array}$ \\
\hline $\begin{array}{l}\text { Operation (ligation and } \\
\text { excision) }\end{array}$ & 9 & 7 \\
Rebanding & $7^{*}$ & $16^{* *}$ \\
Injection & 17 & 13 \\
Thrombosis of & & \\
$\quad$ haemorrhoids & 0 & 2 \\
Treatment of haemorrhoids & & 9 \\
$\quad$ by General Practitioner & 5 & 4 \\
Anal fissure & 1 & 0 \\
Anal fistula & 1 & 1 \\
Rectal prolapse & 1 & 39 \\
Residual symptoms-no & & 49 \\
$\quad$ treatment & 30 & 21 \\
No residual symptoms & 49 & 14 \\
Lost to follow-up & &
\end{tabular}

* Later operation 1.

**Later operation 2 .

\section{Follow-up and final outcome (Table 2)}

Follow-up questionnaires designed to elucidate the nature of any residual symptoms and further treatment were sent to patients who had not attended the hospital within the previous 6 months. Adequate follow-up information was finally obtained for 260 of the 295 patients. The figures in Table 2 are derived both from the answers to these questionnaires (verified where necessary from any further hospital mentioned) and the case records.

Thirty-eight $(28 \%)$ of the patients in Group 1 and $47(29 \%)$ of those in Group 2 required a further course of treatment for haemorrhoids. One of the patients in Group 1 and 4 in Group 2 treated by rebanding, needed a third course of treatment by banding.

Thirty of the patients in Group 1 and 39 of those in Group 2, with a completed questionnaire, had residual symptoms for which no treatment had been sought. The nature of these symptoms is shown in Table 3.

The majority of the patients answering the $c$ questionnaire were prepared to undergo further $\vec{F}$ banding should this prove necessary. However, $17 \stackrel{?}{\rightarrow}$ patients stated that they would not agree to this treatment again.

TABLE 3. Type of residual symptoms in 30 patients in Group 1 and 39 patients in Group 2 with a completed questionnaire, $\omega$ who had sought no treatment for their symptoms

\begin{tabular}{lcc}
\hline \multicolumn{1}{c}{ Symptom } & Group 1 & Group 2 \\
\hline Bleeding & 14 & 31 \\
Lump & 14 & 25 \\
Pain or discomfort & 6 & 23 \\
Irritation & 4 & 6 \\
Discharge or other & 5 & 11 \\
\hline
\end{tabular}

\section{Discussion}

Symptomatic haemorrhoids are the commonest reason for attendance at the out-patient department $ㅇ$ at St Mark's hospital. The logistics of a surgical operation to alleviate the symptoms, includes the creation of a waiting list for admission; this is $\varnothing_{\varnothing}$ unacceptable to both patient and surgeon. The $\frac{\Phi}{3}$ introduction of out-patient methods of treatment $\frac{\Phi}{\square}$ has enormous advantages but cannot in itself be justified unless the morbidity associated with such treatment and the outcome are acceptable. Injection sclerotherapy is well established but other methods of treatment have not been so readily accepted. The success of conservative treatment, however, is $\overline{0}$ reflected in the progressive decline in the number of haemorrhoid operations performed at St Mark's $\stackrel{\varnothing}{\complement}$ hospital: these fell from 305 in 1970 to 143 in 1978. $\overrightarrow{\vec{O}}$

Rubber band ligation was first proposed by $\frac{0}{3}$ Blaisdell (1958) and subsequently modified by $\bar{T}$ Barron (1963). The basic technique has been used at this hospital; at present no more than 2 rubber bands are placed in any treatment session. Eighty-eight 3 . per cent. of patients treated by banding only and $91 \%$ of those having banding and injection, required only one or two sessions of treatment to produce $\delta$ relief of symptoms. The early complications of $₹$ treatment included bleeding in 18 patients $(6 \%)$, 은 severe enough to require admission in 3 patients. $\supset$ Pain or discomfort was experienced by 42 patients $(14 \%)$ after banding and 17 patients who were $\bar{N}$ contacted for follow-up said that they would not 5 undergo the procedure again. Forty-two patients $N$ $(14 \%)$ who were discharged with relief of symptoms required further treatment later: 19 eventually needed a haemorrhoidectomy.

Apart from bleeding, pain or discomfort only $\frac{0}{\Phi}$ $3 \%$ of patients developed complications (Table 2 ). $\stackrel{?}{?}$ Sixty-nine patients had residual symptoms for $\square$ 
which no treatment had been sought and two-thirds of these patients mentioned rectal bleeding. This is a worrying finding as recurrent bleeding may or may not have been due to haemorrhoids. A similar pattern has been found in patients after a haemorrhoidectomy (St Mark's Hospital unpublished data): perhaps patients should be warned before treatment for haemorrhoids that persistent bleeding afterwards calls for further hospital investigation.

This study confirms that rubber band ligation is an effective out-patient treatment for haemorrhoids. Prospective studies are required to determine which of the available treatment methods is most effective in the relief of symptoms and with the least likelihood of long-term recurrence.

\section{Acknowledgments}

This study was carried out with the help of financial assistance from the St Mark's Hospital Research Foundation who were supporting Mr P. J. Jeffery.

\section{References}

BARRON, J. (1963) Office ligation of internal hemorrhoids. American Journal of Surgery, 105, 563.

Blaisdell, P.C. (1958) Prevention of massive hemorrhage secondary to hemorrhoidectomy. Surgery Gynecology and Obstetrics, 106, 485.

Buie, L.A. (1960) Practical Proctology (Second edn), p. 737. Thomas, Springfield, Ill.

EASTMAN, P.E. (1970) Outpatient Hemorrhoidectomy Ligation Technique, p. 13. New York Medical Examination Publishing Co.

GeHAMY, R.A. \& WeAKLEY, F.L. (1974) Internal hemorrhoidectomy by elastic ligation. Diseases of the Colon and Rectum, 17, 347.

Groves, A.R., Evans, J.C.W. \& Alexander-Williams, J. (1971) Management of internal haemorrhoids by rubber band ligation. British Journal of Surgery, 58, 923.

Panda, A.P., Laughton, J.M., Elder, J.B. \& Gillespie, I.E. (1974) The results of outpatient treatment of haemorrhoids by rubber band ligation. Gut, 15, 346 .

SALVATI, E.P. (1970) Ligation of internal haemorrhoids. Proceedings of the Royal Society of Medicine, 63 (Suppl.), 111.

Steinberg, D.M., Liegois, H. \& Alexander-Williams, J. (1975) Long-term review of the results of rubber band ligation of haemorrhoids. British Journal of Surgery, 62 , 144. 